\title{
Investigating the role of c-Jun N-terminal kinases in the proliferation of Werner syndrome fibroblasts using diaminopyridine inhibitors
}

Terence Davis ${ }^{1 *}$, Matthew C Dix², Michal J Rokicki ${ }^{1}$, Amy JC Brook ${ }^{1}$, Caroline S Widdowson², David Kipling ${ }^{1}$ and Mark C Bagley ${ }^{2}$

\begin{abstract}
Fibroblasts derived from the progeroid Werner syndrome show reduced replicative lifespan and a "stressed" morphology, both alleviated using the MAP kinase inhibitor SB203580. However, interpretation of these data is problematical because although SB203580 has the stress-activated kinases p38 and JNK1/2 as its preferred targets, it does show relatively low overall kinase selectivity. Several lines of data support a role for both p38 and JNK1/2 activation in the control of cellular proliferation and also the pathology of diseases of ageing, including type II diabetes, diseases to which Werner Syndrome individuals are prone, thus making the use of JNK inhibitors attractive as possible therapeutics. We have thus tested the effects of the widely used JNK inhibitor SP600125 on the proliferation and morphology of WS cells. In addition we synthesised and tested two recently described aminopyridine based inhibitors. SP600125 treatment resulted in the cessation of proliferation of WS cells and resulted in a senescent-like cellular phenotype that does not appear to be related to the inhibition of JNK1/2. In contrast, use of the more selective aminopyridine CMPD 60 at concentrations that fully inhibit JNK1/2 had a positive effect on cellular proliferation of immortalised WS cells, but no effect on the replicative lifespan of primary WS fibroblasts. In addition, CMPD 60 corrected the stressed WS cellular morphology. The aminopyridine CMPD 6r, however, had little effect on WS cells. CMDP 60 was also found to be a weak inhibitor of MK2, which may partially explain its effects on WS cells, since MK2 is known to be involved in regulating cellular morphology via HSP27 phosphorylation, and is thought to play a role in cell cycle arrest. These data suggest that total JNK1/2 activity does not play a substantial role in the proliferation control in WS cells.
\end{abstract}

\section{Findings}

Werner syndrome (WS) is a genetic disorder where individuals show premature onset of many clinical features of old age and is used as a model to investigate normal aging processes [1]. The molecular mechanism of WS is related to accelerated cell aging. Normal human cells divide a limited number of times before entering replicative senescence [2]. This is postulated to contribute to normal human aging [1] and fibroblasts from WS patients have a much-reduced replicative life span [3]. This premature senescence of WS cells is thought to be a stress response, and the stress-induced p38 MAPK pathway is activated in young WS cells [3]. Treatment with the p38 inhibitor

\footnotetext{
* Correspondence: davist2@cardiff.ac.uk

'School of Medicine, Cardiff University, Heath Park, Cardiff CF14 4XN, UK Full list of author information is available at the end of the article
}

SB203580 increases the growth rate and the cellular life span of primary WS cells to within the range seen for normal fibroblasts, and rescues their senescent-like morphology $[3,4]$. Essentially, SB203580 reverts the phenotypic characteristics of WS fibroblasts, implicating a role for both $\mathrm{p} 38$ and stress signalling in WS.

Although we have shown that p38 is up-regulated in WS cells, consistent with a role for $\mathrm{p} 38$ activation in the accelerated senescence of WS cells [3], SB203580 is known to inhibit other kinases involved in cellular proliferation control, in particular the stress activated JNK1/2 and the CK1 isoforms [5,6], although the involvement of the latter in WS accelerated cell senescence has been ruled out [7]. JNK1/2 are known to activate p53 as a result of increased pro-oxidant state or UV exposure $[8,9]$, and also phosphorylate and stabilise the cyclin

\section{(C) ChemistryCentral}


dependent kinase inhibitor $\mathrm{p} 21^{\mathrm{WAF} 1}[10]$ that is upregulated at (and can induce) cellular senescence [11]. In addition, expression of a constitutively active MKK7 (a JNK1/2 kinase) leads to inhibition of cell proliferation [12]. These data suggest a role for JNK $1 / 2$ in cell cycle arrest in some situations and are consistent with reports that JNK1/2 are not activated in normal fibroblasts, either from young individuals or at low population doublings, but are up-regulated in fibroblasts from aged individuals $[13,14]$ and in senescent WS AG03141 and MRC5 fibroblasts (Figure 1a). Levels of activated JNK1/2 and c-Jun are also elevated in aged skin in vivo [13,15]. Thus the available published data support a role for JNK1/2 in cellular ageing. As JNK1/2 are activated in low PD AG03141 fibroblasts but not in low PD MRC5 cells (Figure 1a), it is plausible that the effect on WS cells of SB203580 is, at least in part, via inhibition of JNK1/2.

Thus we have undertaken a series of experiments using small molecule inhibitors to assess the possible role of JNK1/2 in the proliferation of WS cells (see Additional file 1 for materials and methods). Due to the short supply of primary WS cells, AG03141 cells that have been immortalised using human telomerase (hTERT) have been used to test the effectiveness of inhibitors on cell proliferation prior to using primary cells. AG03141.tert cells preserve the essential features of slow growth rates and aged morphology of primary AG03141 cells [16] and have activated JNK1/2 (Figure 1a).

The most widely used JNK inhibitor is the commercially available anthrapyrazolone SP600125 [17]. Prior to looking at the effects on cell proliferation we titrated the effectiveness of SP600125 to inhibit the anisomycin-induced phosphorylation of c-Jun (Figure 1b). As can be seen, although it does inhibit JNK1/2, SP600125 has relatively low potency, only fully inhibiting JNK1/2 activity above 10 $\mu \mathrm{M}$, in agreement with previous studies that use SP600125 at $25 \mu \mathrm{M}$ to fully inhibit JNK1/2 [17]. SP600125 treatment of WS AG03141.tert cells has an increasingly inhibitory effect on proliferation with concentrations of $10 \mu \mathrm{M}$ and above resulting in complete growth cessation (Figure 1c). At 1.0 and $2.5 \mu \mathrm{M}$ proliferation of the cells is slowed initially with the cells eventually ceasing proliferation after 30 days. The cellular morphology is altered at $10 \mu \mathrm{M}$ SP600125 in that the cells resemble the senescent state, being enlarged and granular (not shown). These data suggest that SP600125 is inducing a cellular senescence-like state in the cells. The cause of this proliferation cessation is unknown, but may not be related to JNK1/2 inhibition, as total JNK activity is not fully inhibited at SP600125 concentrations sufficient to cause the proliferation cessation. However, it has become increasingly clear that SP600125 has low specificity for JNK1/2 [18]. Of particular concern is that SP600125 inhibits the kinases cdk2 and CK1 $\delta$ better than JNK1/2, because cdk2 activity is important for cell cycle progression [19] and CK1 $\delta$ activity is necessary for cell cycle progression and cellular proliferation as shown by CK1 $\delta$ inhibition causing growth arrest [20].

We therefore need JNK inhibitors with improved efficacy and specificity profiles to dissect the possible role for JNK1/2 in WS cell growth. There have been extensive efforts by Pharma to develop novel JNK1/2 inhibitors including, recently, a set of diaminopyridine inhibitors that fits this profile [21]. We therefore synthesised two aminopyridine inhibitors, compound (CMPD) 6o (1) and 6r (2) (Figure 1d) respectively, according to the reported method [21]. These compounds inhibit the activity but not activation of JNK1/2 as shown by JNK1/2 phosphorylation and c-Jun phosphorylation, with $\mathrm{IC}_{50}$ values of approximately $1.5 \mu \mathrm{M}$ in agreement with [21], with maximal inhibition at $10 \mu \mathrm{M}$ for each inhibitor (Figure 1e, f).

Treatment of AG03141.tert cells with inhibitor $\mathbf{1}$ at 10 or $25 \mu \mathrm{M}$ increased their growth rates, although not to the extent seen with SB203580 (Figure 1g). Thus, we tested the effects of $\mathbf{1}$ on the lifespan of primary WS cells. Control AG03141F cells have a total lifespan of 16.5 PD (including the $12 \mathrm{PD}$ that the cells achieved prior to receipt from the Coriell Cell Repository); this is increased to $26.3 \mathrm{PD}$ by the use of SB203580 (Figure 1h). Inhibitor 1 at $10 \mu \mathrm{M}$ had no effect on the growth rate or lifespan of AG03141F cells compared to the DMSO control (Figure $1 \mathrm{~h}$ ), whereas at $25 \mu \mathrm{M}$ growth was arrested (not shown). Cellular morphology in control AG03141F cultures was one of enlarged cells with F-actin stress fibres; treatment with 1 resulted in a reversion to the small cell morphology and sparse F-actin stress fibres that is characteristic of wild-type fibroblasts (Figure 1j: see [4] for morphology of normal fibroblasts).

JNK1/2 have not been reported to affect F-actin stress fibre production. Unexpectedly (see [21]), it was found that in addition to inhibiting JNK1/2, inhibitor 1 inhibits the $\mathrm{p} 38$-signalling pathway as assessed by the prevention of anisomycin-induced HSP27 phosphorylation (Figure 1i). On further analysis, inhibitor 1 appears to be a weak inhibitor of MK2 (the major HSP27 kinase), because it does not prevent the activation of MK2 by p38 (as shown by the continued presence of the band shift indicative of MK2 phosphorylation at high $\mathbf{1}$ concentrations; see Figure $1 \mathrm{k}$ lane 4 ), but instead prevents the phosphorylation of HSP27 (Figure 1k).

In contrast inhibitor 2 had little effect on the proliferation of AG03141.tert cells up to $10 \mu \mathrm{M}$, although it is growth inhibitory at $25 \mu \mathrm{M}$ (Figure $1 \mathrm{~g}$ ), a point that coincides with activation of the p38 pathway (Figure 1i). Inhibitor 2 slightly reduced the replicative lifespan of AG03141F cells (Figure 1h), but had very little effect on the cellular morphology phenotype (Figure 1j).

Overall the data suggest that total JNK1/2 activity is not involved in the slow growth phenotype of WS cells, 


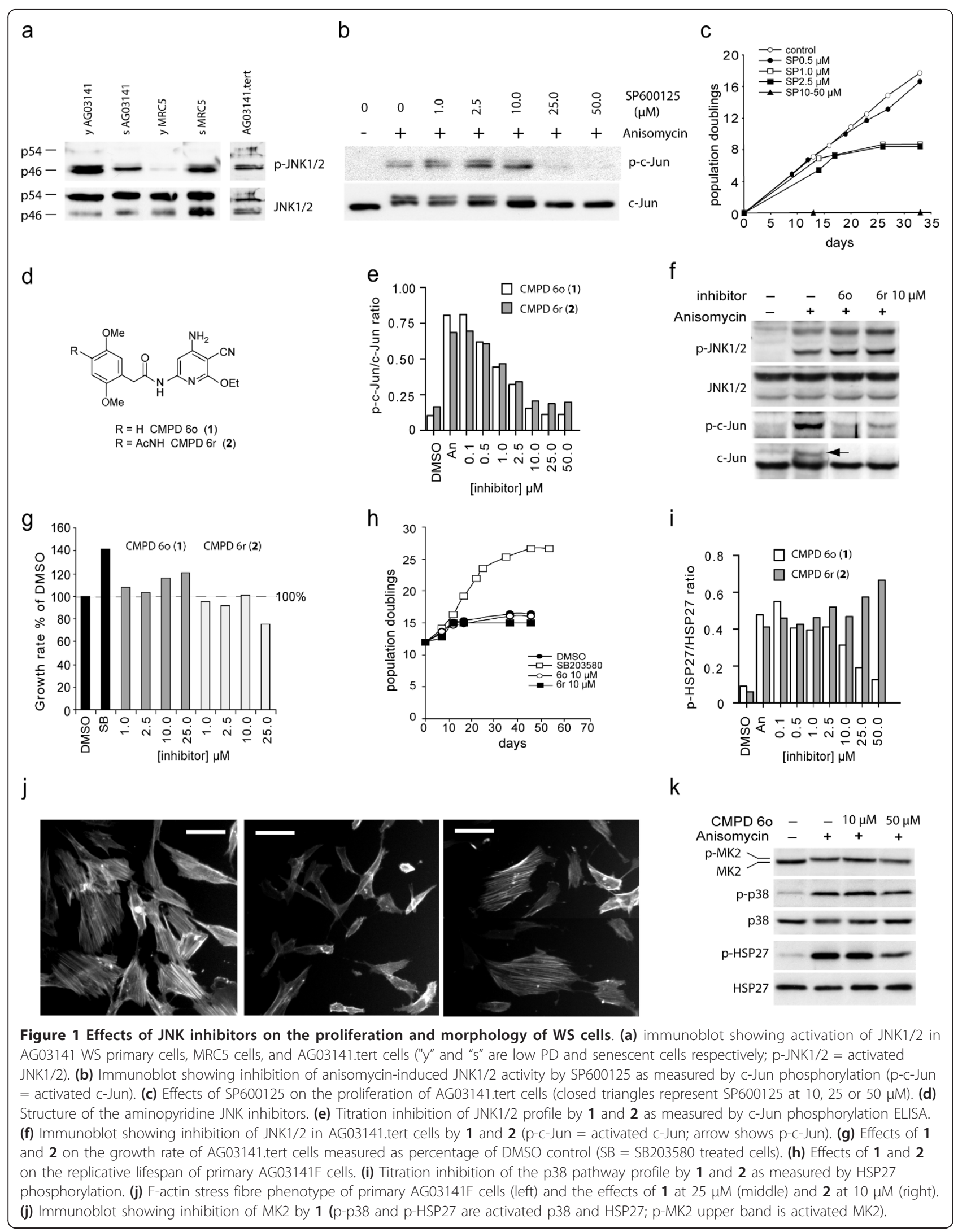


or in their aged (stressed) cellular morphology. Further, the observation that complete inhibition of JNK $1 / 2$ using 1 and $\mathbf{2}$ does not result in cell cycle arrest, suggests that the proliferation arrest resulting from SP600125 use is not through inhibition of JNK1/2, a possibility supported by recent data showing that SP600125 can induce a $G_{2} / M$ cell cycle arrest via $\mathrm{p} 21^{\mathrm{WAF} 1}$ expression and cdk2 inhibition, although the mechanism is not fully understood [22].

However, as both 1 and 2 completely inhibit both JNK1 and JNK2 at $10 \mu \mathrm{M}$, these data do not rule out the possibility that individual JNK isoforms may be separately involved. On this note data from mouse JNK knockouts suggest that JNK1 promotes whereas JNK2 inhibits proliferation in mouse fibroblasts [23]. In addition, as more data is obtained it is increasingly clear that the biological role of JNKs in human disease processes may well be isoform specific [24]. Thus as SB203580 preferentially inhibits JNK2 isoforms at the concentration where it is most effective in WS cells $[3,5,18]$, it may be that the effectiveness of SB203580 on the prevention of accelerated ageing in WS fibroblasts results from the inhibition of both p38 and JNK2 isoforms. Thus, inhibitors that can target each specific JNK isoform separately are necessary to dissect out these individual roles [24].

In conclusion we have synthesised two potent and selective JNK inhibitors and tested their effects on the proliferation of WS cells. While our data exclude a role for total JNK activity on WS cell proliferation or morphology, they do suggest a possible role for MK2. It cannot be excluded that JNK is involved in WS cell growth, but in an isoform-specific manner, a possibility that can only be addressed once suitable isoform-specific inhibitors become available. Finally, these data illustrate the greater utility of these diaminopyridine inhibitors for the study of the role of JNKs in biological systems, rather than the anthrapyrazolone SP600125.

\section{Additional material}

Additional file 1: Methods. Word file documenting materials and methods used in this work.

\footnotetext{
Acknowledgements

This work was supported by grants from the Biotechnology and Biological Sciences Research Council Selective Chemical Inhibition of Biological Systems (BB/D5241401) and Economic and Social Research Council New Dynamics of Ageing (RES-356-25-0024) initiatives, and the Engineering and Physical Sciences Research Council (GR/S25456; DTA award to CSW).

\section{Author details}

${ }^{1}$ School of Medicine, Cardiff University, Heath Park, Cardiff CF14 4XN, UK. ${ }^{2}$ School of Chemistry, Main Building, Cardiff University, Park Place, Cardiff CF10 3AT, UK.
}

\section{Authors' contributions}

TD participated in study design and coordination, manuscript preparation, and carried out growth experiments, MJR carried out the immunoassays and ELISA assays, AJCB carried out growth experiments, MCD synthesised the inhibitors, CSW helped with inhibitor synthesis, MCB participated in study design, helped synthesise the JNK inhibitors, and helped to draft the manuscript, DK conceived the study, participated in its design and coordination and helped to draft the manuscript. All authors read and approved the final manuscript.

\section{Competing interests}

The authors declare that they have no competing interests.

Received: 13 October 2011 Accepted: 8 December 2011 Published: 8 December 2011

\section{References}

1. Kipling D, Davis T, Ostler EL, Faragher RGA: What can progeroid syndromes tell us about human aging? Science 2004, 305:1426-1431

2. Hayflick L, Moorhead PS: The serial cultivation of human diploid cell strains. Exp Cell Res 1961, 25:585-621.

3. Davis T, Baird DM, Haughton MF, Jones CJ, Kipling D: Prevention of accelerated cell aging in Werner syndrome using a p38 mitogenactivated protein kinase inhibitor. J Gerontol A Biol Sci Med Sci 2005, 60:1386-1393.

4. Davis T, Kipling D: Assessing the role of stress signalling via $\mathrm{p} 38 \mathrm{MAP}$ kinase in the premature senescence of Ataxia Telangiectasia and Werner syndrome fibroblasts. Biogerontology 2009, 10:253-266.

5. Godl K, Daub H: Proteomic analysis of kinase inhibitor selectivity and function. Cell Cycle 2004, 3:393-395.

6. Bagley MC, Davis T, Rokicki MJ, Widdowson CS, Kipling D: Synthesis of the highly selective p38 MAPK inhibitor UR-13756 for possible therapeutic use in Werner syndrome. Future Med Chem 2010, 2:193-201.

7. Davis T, Bachler MA, Wyllie FS, Bagley MC, Kipling D: Evaluating the role of p38 MAP kinase in growth of Werner syndrome fibroblasts. Ann N Y Acad Sci 2010, 1197:45-48.

8. Oleinik NV, Krupenko NI, Krupenko SA: Cooperation between JNK1 and JNK2 in activation of p53 apoptotic pathway. Oncogene 2007, 26:7222-7230.

9. Wu GS: The functional interactions between the p53 and MAPK signaling pathways. Cancer Biol Ther 2004, 3:156-161.

10. Kim GY, Mercer SE, Ewton DZ, Yan Z, Jin K, Friedman E: The stressactivated protein kinases $\mathrm{p} 38$ alpha and JNK1 stabilize p21(Cip1) by phosphorylation. J Biol Chem 2002, 277:29792-29802.

11. Brown JP, Wei W, Sedivy JM: Bypass of senescence after disruption of p21CIP1/WAF1 gene in normal diploid human fibroblasts. Science 1997, 277:831-834.

12. Wolter S, Mushinski JF, Saboori AM, Resch K, Kracht M: Inducible expression of a constitutively active mutant of mitogen-activated protein kinase kinase 7 specifically activates c-JUN NH2-terminal protein kinase, alters expression of at least nine genes, and inhibits cell proliferation. J Biol Chem 2002, 277:3576-3584.

13. Kuma Y, Sabio G, Bain J, Shpiro N, Marquez R, Cuenda A: BIRB796 inhibits all p38 MAPK isoforms in vitro and in vivo. $J$ Biol Chem 2005, 280:19472-19479.

14. Wang Y, Meng A, Zhou D: Inhibition of phosphatidylinostol 3-kinase uncouples $\mathrm{H} 2 \mathrm{O} 2$-induced senescent phenotype and cell cycle arrest in normal human diploid fibroblasts. Exp Cell Res 2004, 298:188-196.

15. Chung JH, Kang S, Varani J, Lin J, Fisher GJ, Voorhees JJ: Decreased extracellular-signal-regulated kinase and increased stress-activated MAP kinase activities in aged human skin in vivo. J Invest Dermatol 2000, 115:177-182.

16. Davis T, Haughton MF, Jones CJ, Kipling D: Prevention of accelerated cell aging in the Werner syndrome. Ann N Y Acad Sci 2006, 1067:243-247.

17. Bennett BL, Sasaki DT, Murray BW, O'Leary EC, Sakata ST, Xu W, Leisten JC, Motiwala A, Pierce S, Satoh Y, Bhagwat SS, Manning AM, Anderson DW: SP600125, an anthrapyrazolone inhibitor of Jun N-terminal kinase. Proc Natl Acad Sci USA 2001, 98:13681-13686.

18. Bain J, Plater L, Elliott M, Shpiro N, Hastie CJ, McLauchlan H, Klevernic I, Arthur JS, Alessi DR, Cohen P: The selectivity of protein kinase inhibitors: a further update. Biochem J 2007, 408:297-315. 
19. Lee $M H$, Yang $H Y$ : Regulators of G1 cyclin-dependent kinases and cancers. Cancer Metastasis Rev 2003, 22:435-449.

20. Peters JM, McKay RM, McKay JP, Graff JM: Casein kinase I transduces Wht signals. Nature 1999, 401:345-350.

21. Szczepankiewicz BG, Kosogof C, Nelson LT, Liu G, Liu B, Zhao H, Serby MD Xin Z, Liu M, Gum RJ, Haasch DL, Wang S, Clampit JE, Johnson EF, Lubben TH, Stashko MA, Olejniczak ET, Sun C, Dorwin SA, Haskins K, AbadZapatero C, Fry EH, Hutchins CW, Sham HL, Rondinone CM, Trevillyan JM: Aminopyridine-based c-Jun $\mathrm{N}$-terminal kinase inhibitors with cellular activity and minimal cross-kinase activity. J Med Chem 2006, 49:3563-3580.

22. Moon DO, Choi YH, Kim GY: Role of p21 in SP600125-induced cell cycle arrest, endoreduplication, and apoptosis. Cell Mol Life Sci 2011, 68:3249-3260.

23. Sabapathy K, Hochedlinger K, Nam SY, Bauer A, Karin M, Wagner EF: Distinct roles for JNK1 and JNK2 in regulating JNK activity and c-Jundependent cell proliferation. Mol Cell 2004, 15:713-725.

24. Bogoyevitch MA, Ngoei KR, Zhao TT, Yeap YY, Ng DC: c-Jun N-terminal kinase (JNK) signaling: recent advances and challenges. Biochim Biophys Acta 2010, 1804:463-475.

doi:10.1186/1752-153X-5-83

Cite this article as: Davis et al:: Investigating the role of c-Jun Nterminal kinases in the proliferation of Werner syndrome fibroblasts using diaminopyridine inhibitors. Chemistry Central Journal 2011 5:83.

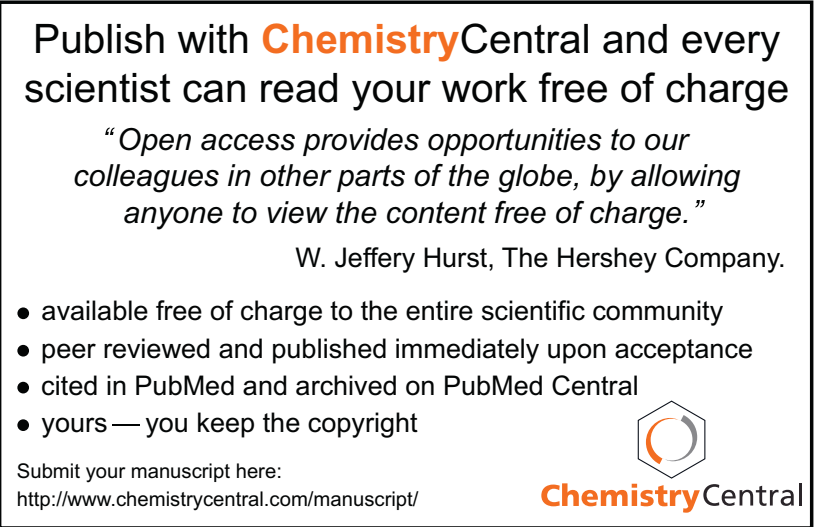

